\title{
LOS ALICATADOS DEL BAÑO DE COMARES DE LA ALHAMBRA, ¿ISLÁMICOS O CRISTIANOS?
}

\author{
POR \\ Ma Elena DíEz Jorge \\ Universidad de Granada
}

Los alicatados del Baño de Comares en la Alhambra han generado a lo largo de la historia un intenso debate acerca de su origen, islámico o cristiano. En este trabajo se aportan nuevos datos, esencialmente procedentes de los archivos, y que contribuyen a reflexionar sobre su procedencia e historia a la vez que nos permiten tener elementos de referencia ante futuras restauraciones.

Palabras Clave: Cerámica arquitectónica; Alicatados; Baño de Comares; Alhambra.

The tiling with arabesque designs lining the walls of the Comares Bath in the Alhambra has long been the subject of an intense debate concerning their origin: Islamic or Christian. The author offers new data, mainly archival, leading to new reflections on their origin and history, as well as providing referential elements in the face of possible future restorations.

KEY wORDs: architectural ceramics, arabesque tiles, Comares Bath, Alhambra.

Uno de los espacios que más ha llamado la atención de la Alhambra de Granada ha sido el Baño de Comares. Desde fechas cercanas a la conquista cristiana ya se tienen noticias de la admiración que despertaba, asociándose a partir de entonces a diversos tipos de leyendas. Más allá del imaginario que de este espacio se fue creando es bien cierto que todavía hoy encierra dudas sobre algunos de sus aspectos constructivos, funcionales y ornamentales. Entre ellos, el origen de sus alicatados ha sido quizás una de las grandes preguntas sin resolver. ${ }^{1}$

\footnotetext{
${ }^{1}$ El siguiente trabajo surgió a partir de la investigación llevada a cabo por encargo del Patronato de la Alhambra y el Generalife siendo entonces su director D. Mateo Revilla Uceda, a quien agradezco la confianza depositada y su afán por intentar documentar lo mejor posible los alicatados antes de proceder a una posible restauración. Quiero agradecer también a D. Antonio Orihuela Uzal, de la Escuela de Estudios Árabes (CSIC), su ayuda prestada en la búsqueda bibliográfica de algunas referencias.
} 


\section{Los alicatados en la Alhambra}

Junto con las yeserías y las techumbres de lazo, los alicatados constituyen un elemento principal en la decoración arquitectónica de la Alhambra. No se puede estudiar la arquitectura de la Alhambra sin tener en cuenta estos aspectos ya que son los que definen visualmente la forma, el volumen e incluso en algunos casos la funcionalidad.

La cerámica arquitectónica de la Alhambra constituye un capítulo aún sin estudiar. ${ }^{2}$ Sin duda se hace necesario elaborar un corpus de los tipos, técnicas y cronología empleados en la cerámica arquitectónica de la Alhambra, aunque es realmente complejo y laborioso pero constituiría un documento de gran valor tanto para la investigación como para las futuras restauraciones en el conjunto monumental.

\subsection{Sobre su origen, técnicas y terminología}

Si nos centramos en los alicatados tradicionalmente se piensa especialmente en al-Andalus y el Magreb. Algunos autores han establecido la importancia del área turco-iraní en el siglo XI para conocer el origen de los alicatados. ${ }^{3}$

Se habla del zillij para hacer referencia a la técnica de los alicatados, señalándose la estrecha relación entre al-Andalus y "Marruecos", indicando en algunos casos el núcleo exportador en al-Andalus, ya que la técnica se lleva al Norte de África por la emigración de judíos y musulmanes; en otros casos se plantea que se deben revisar las teorías acerca de la influencia de la Alhambra en la producción del zillij, afirmándose que esas técnicas de alicatados ya existían en Fez. ${ }^{4}$ Algunos autores señalan que el zillij aparece en el Magreb y al-Andalus ya en el siglo XII y XIII, conservándose restos en el minarete de la Kutubbiyah, donde se utiliza el blanco y verde turquesa, también en la qasba de Marrakesh, así como en la Torre del Oro y Plata en Sevilla, refiriéndose claramente a la época almohade ya que en la omeya en al-Andalus se señala que más que los alicatados lo que se utilizaron fueron las teselas y el opus sectile continuando con la tradición romana y bizantina. Las formas más conocidas del alicatado florecen a finales del siglo XIII y principios del XIV, apareciendo simultáneamente en diversas zonas y entre ellas Granada. ${ }^{5}$

Para algunos estudiosos el mundo de al-Andalus se caracteriza por el tratamiento de los zócalos con especial atención en su decoración, cuya explicación se encuentra en parte en el hecho de que no existe un mobiliario alto, sino que las personas se sientan a nivel del suelo y el punto visual desciende. En los zócalos se suele emplear la pintura o los alicatados, señalándose que hay zonas de gran tradición azulejera como la de la región levantina en la Baja Edad Media, época en que se introduce fundamentalmente la cerámica arquitectónica. En lo que se refiere a la pintura mural de al-Andalus, especialmente en el caso nazarí, no ha sido estudiada en su conjunto; además lo que conocemos corresponde principalmente a residencias palaciegas. Se ha señalado que en estos palacios la pintura mural corresponde a los lugares más íntimos de la residencia mientras que en las salas de aparato se prefieren los alicatados. ${ }^{6}$

\footnotetext{
2 No me resisto a nombrar a una de las máximas estudiosas de la cerámica arquitectónica, específicamente en el ámbito aragonés y cuyo trabajo es fundamental para toda aquella persona que se dedique al estudio de la cerámica arquitectónica. Me refiero a $\mathrm{M}^{\mathrm{a}}$ Isabel Álvaro Zamora con múltiples trabajos sobre la cerámica aragonesa y en los últimos años con especial dedicación a la cerámica arquitectónica. En el caso específico de Granada, hay que citar el importante trabajo llevado a cabo en GómEz-MoRENo CALERA, José Manuel. "La cerámica arquitectónica en el mudéjar granadino". Cuadernos de Arte de la Universidad de Granada, 36, 2005, pp.9-27.

3 Cfr. ZozAYA, Juan. "Alicatados y azulejos hispano-musulmanes: los orígenes", en La céramique médiévale en Mediterranée. Actes du VI Congrés de l'Association Internatonale pour l'étude des céramiques médiévales en Méditerranéenne. Aix-en-Provence, 1997, pp.601-613.

4 Vid. Benassa, Mohamed. "The art in context", en Hedgecoe, John y Damluji, Salma Samra. Zillij. The art of Moroccan ceramics. United Kingdom, 1992, pp. 16-39.

5 Cfr. Erzini, Nadia. “The Titwan School”, en Hedgecoe, John y Damluji, Salma Samra. Op. cit., p 142-201.

${ }^{6}$ Cfr. Rallo Gruss, Carmen. Aportaciones a la técnica y estilística de la pintura mural en Castilla a final de la Edad Media. Tradición e influencia islámica. Madrid, 2002, p. 195.
} 
En el caso del alicatado nazarí los colores son el azul, verde, marrón púrpura y el amarillo ocre. Las piezas son cortadas del panel vidriado por el albañil y a golpe de piqueta, aunque también se experimentaba con una técnica alternativa que era cortar la piezas antes de ser vidriadas con un latón o plomo templado y más tardíamente se hará con moldes de hierro. ${ }^{7}$ En el caso de al-Andalus, según González Martí, se dibujaba en un tablero el tema y se cortaban las losetas de las piezas del color que exigía la composición para irlas colocando sobre el dibujo con la superficie barnizada hacia abajo, después se vertía una capa de mortero de cal si el alicatado era para el pavimento y de yeso si se había de fijar en la pared. ${ }^{8}$

El momento álgido de los alicatados islámicos en la Alhambra es el siglo XIV, continuándose su elaboración hasta el fin del período nazarí. ${ }^{9}$ Desconocemos si en época nazarí se produjeron reposiciones de piezas vidriadas, pero en la época cristiana las reposiciones y nuevas formas y técnicas de alicatados y azulejos fueron frecuentes y enriquecieron la Alhambra, poniéndose piezas tradicionales e introduciendo nuevos tipos durante los siglos posteriores. De lo que hemos encontrado en la documentación se habla por lo general de maestro de azulejos a lo largo del XVI, mientras que en el XVII aparece el término chapador de azulejos. Por otro lado, en lo que se refiere a la denominación de las piezas, según González Martí, en la época medieval se utiliza el nombre de alicatados, pero hasta la fecha no hemos encontrado el uso de este término en la documentación de la Alhambra sino ya en época más reciente. En la documentación manejada se suele emplear el término "azulejo", "piezas vidriadas", u otros más específicos. ${ }^{10}$ A finales del siglo XV los pagos documentados por piezas vidriadas en la Alhambra se hacen por lo general por varas mientras que a partir del siglo XVI y en adelante lo frecuente será el pago por cada una de las piezas vidriadas.

\subsection{Reposiciones y nuevos alicatados tras la conquista cristiana}

De los primeros años tras la conquista destacamos en primer lugar el hecho de contratar encargos de piezas a maestros azulejeros fuera de la ciudad de Granada, concretamente a maestros de Jaén y de Sevilla. El hecho de hacer uso de estos maestros azulejeros no quiere decir que no hubiera en Granada sino que quizás hubiera un desconocimiento de buenos maestros que estuvieran en la ciudad.

Sobre estos maestros foráneos a Granada los datos son muy claros ya que hacen referencia a Antón Jiménez, maestro de azulejos y vecino de Jaén, así como a Juan Ruiz de la Cruz, vecino de Andújar. Los encargos son realizados entre 1497 y 1499 y se trata de azulejos de lazo sin especificar más que son para las casas reales y varas de azulejos para la Sala de quadras (guardas) en el Palacio de los Leones. ${ }^{11}$ Pero los encargos

\footnotetext{
${ }^{7}$ Cfr. ERZINI, Nadia. Op. cit., p 161-162.

8 GonZÁlez Martí, Manuel. Cerámica del levante español. Siglos medievales. Tomo II, alicatados y azulejos. Barcelona, 1952, p. 114.

${ }^{9}$ Interesante resulta el trabajo de Juan Zozaya al analizar los alicatados en la Alhambra referenciándolos con otros casos y centros productores de al-Andalus y del período mudéjar. ZOZAYA, Juan. Op. cit.

10 Términos como adeferas, olambrilla, alizar (a veces se especifica de marca mayor), almenillas, azulejo(es el más utilizado en los encargos para los baños); además de por el tamaño se especifican variedades como azulejos cangrejos, azulejos moriscos, azulejos de banda, azulejos de hechura de pie (pico?) de Aguila, cinta (además de por tamaños se especifican cintas romanas), corona, frailes, jairas, "llaranxada" (sic), mostagueras, signo, tablitas, triángulos, verduguillos.

${ }^{11}$ El 23 de octubre de 1497 se pagan 2530 maravedíes a Juan Ruiz de la Cruz por "doze varas de azulejos que del se conpraron para los Bañyos de las Casas Reales de la dicha Alanbra y del traer los dichos azulejos dende la dicha Andújar fasta las dichas Casas Reales", AGS (Archivo General de Simancas), CMC (Contaduría Mayor de Cuentas), leg. 140, pliego de dos folios de cuentas relativas a 1497, cit. fol. 2r). A Antón Jiménez se le encarga hacer y labrar azulejos para las casas reales en 1497, AGS, CMC, $1^{\text {a }}$ época, leg. 140. También a Antón Jiménez se documenta el pago de 1707'5 maravedíes en cumplimiento de 12262 ' 5 maravedíes por 81 varas y media y un cuarto de azulejos para la sala de las cuadras (guardas?) en el Palacio de los Leones, AGS, C y SR (Casas y Sitios Reales), leg. 44, no 28 , fol. 18 vto, y 23 vto. (se trata de cuentas transcritas en 1501 sobre maestros, carpinteros y albañiles a los que se pagaron por las obras en los palacios reales de la Alhambra y que corresponden desde el 10 de septiembre de 1498 hasta 5 de Junio de 1499).
} 
documentados más importantes son los que hacen alusión a maestros sevillanos. Se cita a Fernand Martínez Guijarro y a Alonso Sancho de Carmona, así como los pagos por el transporte de azulejos. ${ }^{12}$

En segundo lugar, se trata de encargos en general sin especificar el lugar al que van destinados, con lo que difícilmente podemos saber si se trata de piezas para un mismo espacio y entonces, por la cantidad, tendríamos que pensar en un nuevo alicatado más que en una reposición. Además de los pagos para los baños y que recogemos en el apartado siguiente, sólo hemos podido constatar de manera clara un encargo de azulejos para el Palacio de los Leones que se realiza entre septiembre de 1498 y Junio de 1499 a Antón Jiménez, maestro de azulejos.

En el resto de pagos no se especifican los espacios a los que van destinadas las piezas. En 1495 encontramos dos encargos al maestro de azulejos. En 1496 y en 1497 un pago cada año por ciertos azulejos. En 1498 un pago y el encargo a Juan Ruiz de la Cruz por varas de azulejos para las casas reales. En 1499 hay más referencias sobre pagos a maestros de azulejos señalándose varas de azulejos y alizares. ${ }^{13}$ En general se trata de azulejos de lazo, de alizares y especialmente azulejos sin especificar forma ni color. Entre los pagos se documentan materiales como aceite y estopa para el trabajo de los maestros azulejeros. Los encargos en el año 1500 son especialmente de azulejos traídos de Sevilla. ${ }^{14}$

Del total documentado en esos cinco años, 1495-1500, y exceptuando los pocos datos especificados para los baños, hay una inversión de 92668'5 maravedíes en piezas vidriadas. Hay que tener en cuenta que estos son los datos que nos han llegado ya que estas cuentas de Simancas sólo recogen donde empieza el pago y donde termina, no conociendo las cuentas desglosadas por completo, además de que hay piezas de las que no se indica más que el encargo pero no nos ha llegado el precio o viceversa. No obstante, más que por la cantidad de maravedíes, por lo que destacan estos datos es por la cantidad de piezas vidriadas encargadas que implica ese dinero. Si tomamos como media 3 maravedíes por pieza, y sin contar las destinadas a los baños, nos podría salir un cálculo aproximado de cerca de 31000 piezas vidriadas, que lógicamente no debieron ser exclusivamente para simples reposiciones sino que debemos pensar en forramientos nuevos o reposiciones casi completas. ${ }^{15}$

\subsection{El esplendor del siglo XVI, la confusión cultural}

Hay una actividad importante de pagos de piezas vidriadas a lo largo del XVI, siendo hasta la fecha el momento en que más encargos se hacen. Durante la primera mitad del XVI se documentan, además de las piezas para los baños, piezas vidriadas de las que no se especifica el lugar al que van destinadas, salvo algún dato como el pago en 1539 a Francisco Sánchez, solador, por cortar ladrillos y asentar azulejos y alizares

12 AGS, CMC, $1^{\circ}$ época, leg. 140.

13 En 1495 se pagan 1000 maravedíes al maestro de azulejos y en diciembre del mismo año se encargan tres mil azulejos. En 1496 se pagan 1406 maravedíes por ciertos azulejos. En 1497 un pago de 1069'5 maravedíes por ciertos azulejos. En 1498 un pago de 892 maravedíes por la compra de azulejos de lazo y un encargo a Juan Ruiz de la Cruz por 750 maravedíes de cuatro varas de azulejos para las casas reales. En 1499, de febrero a junio, se documentan pagos por 8070'5 maravedíes al maestro de azulejos por piezas para las casas reales; entre los pagos de junio al maestro de azulejos por piezas para las obras de las casas reales se anotan 625 maravedíes por cinco varas de azulejos y 205 maravedíes por 40 alizares; en junio del mismo año se pagan 26 azulejos y también seis alizares, estos últimos a tres maravedíes cada uno para los escalones de la entrada de la sala; en julio por 236 azulejos a tres maravedíes y medio cada uno, por 46 alizares a cinco maravedíes cada uno, por diez panillas de aceite y una libra de estopa para los maestros de azulejos; en septiembre por 16 alizares a seis maravedíes cada uno así como al mozo con un asno por varios días por acarrear alizares. AGS, CMC, $1^{\circ}$ época, leg. 140

14 Diez acémilas cargadas de azulejos desde Sevilla a Granada; un pago a Fernando Martínez Guijarro de 8742’5 maravedíes por cierto azulejo que envió desde Sevilla a Granada; a Diego de Vadillo 4500 maravedíes por nueve cargas de azulejos desde Sevilla; a Pedro Dias de Vadillo 5000 maravedíes por 10 cargas de azulejos desde Sevilla; a Alonso Sancho de Carmona 8815 maravedíes en cumplimiento de 12815 maravedíes por azulejos. AGS,CMC, $1^{\text {a }}$ época, leg. 106; AGS, Cy SR, leg. 44, $n^{\circ} 28$.

${ }^{15}$ Según la documentación de estos años se suele manejar un precio entre tres y tres maravedíes y medio por pieza, a excepción de 46 alizares que se especifican a cinco y 16 alizares a seis maravedíes. 
grandes para el Mexuar y el Cuarto Dorado. Los pagos son esencialmente a Juan Pulido,de Sevilla, y a Isabel de Robles, cristiana vieja de Granada que estuvo casada con el alfarero morisco Alonso Hernández. ${ }^{16}$ Para uno y otra se trata de pagos por piezas vidriadas efectuados esencialmente desde 1537 hasta 1546, ya que de los años inmediatamente anteriores y posteriores no se conservan los cuadernos de nóminas y en el resto de la documentación no hemos encontrado rastro de ellos. Los datos sobre Juan Pulido se concentran entre 1542 y 1546 . Se trata de azulejos, algunas piezas de azulejos de desecho y ladrillo de azulejos. En la documentación se conservan los pagos realizados por el transporte desde Sevilla. En cuanto a Isabel de Robles se trata de cargas de azulejos en los que no especifica el lugar al que van destinados, a excepción de las importantes indicaciones sobre los Baños. Son pagos por azulejos, en general de mayor precio y variedad que los de Juan Pulido: azulejos de diversos precios, tejas grandes verdes y blancas para los tejados de la casa real, tablillas de azulejos, ladrillos prietos, alizares, cintas, olambres y romanos.

A finales del siglo XVI los encargos se concentran en el Palacio de Comares, llegando hasta los primeros años del siglo XVII. Se trata de importantes cantidades para solado y revestimiento de las salas de Comares y especialmente para el Patio de Comares, recayendo los encargos principalmente en Antonio Tenorio y Gaspar Hernández. Por la cantidad de piezas debemos pensar en un revestimiento completo y nuevo del patio. ${ }^{17}$ También se encargan piezas para el Cuarto de Comares, aunque en este caso se especifica que es para reparar los forros de las paredes de azulejos. ${ }^{18}$

En cuanto al Palacio de los Leones también hay constancia de piezas vidriadas aunque en menor número que en el Palacio de Comares: mostagueras, tablillas, tejas y ladrillo vidriado componen algunos pagos. ${ }^{19}$ Llama la atención el encargo para solar el patio del Cuarto de los Leones de mostagueras vidriadas a Antonio Tenorio en 1585, corroborando de este modo la calcografía dibujada muy posteriormente por Henri Swinburne para Travels through Spain in the Years 1775 and 1777 donde aparece el suelo del Patio de los Leones con piezas de colores. En 1599 se documentan pagos de azulejos para reparar el patio y corredores: alizares verdes para la grada de subida del patio a los corredores, y de colores blanco azul, verde y negro en el solado y almenilla como remate del zócalo de azulejos en el testero de la Sala de Mocárabes. Para la Sala de Abencerrajes se documentan encargos en 1584 y 1586 al azulejero Antonio Tenorio de mostagueras vidriadas de colores, coronas de azulejos de colores, cintas romanas, cintas pequeñas, alizares; también cintas romanas y ladrillos vidriados para acabar de solar y forrar la Sala de Abencerrajes. ${ }^{20}$

Con estos datos, y lo que en la actualidad vemos, no es difícil averiguar que los azulejos de arista de la Sala de Abencerrajes son del XVI. Del mismo modo, la documentación nos lleva a afirmar que una gran parte de los alicatados del Patio de Comares son también de esta época, aunque siguiendo las técnicas y formas nazaríes. Más complejo resulta saber el nivel de porcentaje de piezas repuestas en el XVI en el Salón de Comares o en algunos espacios del Palacio de los Leones, así como los posibles espacios que se forraron en el XVI sin que lo estuvieran en el período nazarí. Todo ello nos muestra la complejidad de este conjunto monumental, y si se quiere la "confusión cultural", así como la prudencia que requiere cualquier afirmación sobre la cronología de algunos de sus principales componentes.

En el XVII siguieron los trabajos de reposición de piezas vidriadas en alicatados nazaríes o en aquellos iniciados en el siglo XVI. Documentamos piezas para el Patio de Arrayanes y el Salón de Comares. ${ }^{21} \mathrm{Se}$

16 Vid. DíEz Jorge, Ma Elena." La mujer y su participación en el ámbito artesanal". Cuadernos de Arte de la Universidad de Granada, 29, 1998, pp. 173-181; Idem. "Mujeres en la Alhambra: Isabel de Robles y el Baño de Comares". Cuadernos de Arte de la Universidad de Granada (en prensa).

17 Se trata de olambrillas, mostagueras, tablillas de azulejos de colores, cintas blancas, signos y piezas de almenillas con dos cintas verdes, una por lo alto y otra por lo bajo para revestimiento del patio. A.Alh. (Archivo de la Alhambra), L-240-6; A. Alh., L- 240-7.

18 Tablillas de azulejos de colores, azulejos moriscos, cuadradas de labores, jairas blancas y azules, piezas de azulejos de banda, tablitas amarillas y negras, verduguillos verdes y alizares. A-Alh., L-240-6; A.Alh., L-21-4, no 3.

19 A-Alh. L-5-40; A.Alh. L-5-23; Alh. L-240-2; A.Alh. L-240-3; A.Alh., L- 240-4.

20 A.Alh. L-240-4, A-Alh. L-240-5.

21 A.Alh., L-152-1, cuaderno de reparo en las casas reales del siglo XVII, fol. 2 vto. 
continuaron los trabajos en el Patio de los Leones encargados ahora a Pedro Tenorio. ${ }^{22}$ Como obra nueva de alicatados y azulejos hemos encontrado las llevadas a cabo en el Jardín de los Mármoles y su entorno, documentándose bastantes ladrillos así como pagos al maestro azulejero Pedro Tenorio a lo largo de 1626 por azulejos, olambres, verduguillos, adeferas y alizares. Se trata de piezas para solar y forrar las paredes y jardines de los Mármoles que están al lado del Cuarto Real de las Frutas, a la entrada de los baños; también en el callejón que está a la entrada de dicho jardín así como las paredes de la bóveda que se repara bajo el cuarto de Comares. ${ }^{23}$

En el siglo XVIII el abandono debía ser manifiesto, como se constata en un documento al indicarse la multitud de robos que se cometen, exponiéndose diversas medidas para la conservación y mantenimiento de la Alhambra. Entre los deterioros se señala la falta de muchos lienzos de pared sin azulejos en los palacios y en el Generalife. ${ }^{24}$ Aunque se documentan algunos pagos de azulejos para las casas reales, no se especifican los espacios a los que van destinadas las piezas. ${ }^{25}$ También se indica la necesidad de enchapaduras del suelo y cenefas para los interiores de la casa real para lo cual se hace una previsión de azulejos y maestros. ${ }^{26}$

En los siglos XIX y XX constatamos reparaciones, aunque hay poca documentación clara al respecto utilizándose, además de nuevas piezas, otras de los almacenes para completar paños de los alicatados, como hiciera Leopoldo Torres Balbás, criterio en mi opinión discutible porque genera una mayor confusión, máxime cuando no se ha realizado el corpus y catalogación de los alicatados y no se ha estudiado de manera global ni pormenorizada los paños de alicatados. Esos criterios de restauración llevan a dudar de si se trata de un paño nazarí con reposiciones posteriores o de un paño posterior a la época nazarí con reposiciones de piezas nazaríes, dificultando conocer qué estaba alicatado en la época islámica.

\section{El Baño de Comares}

Dentro de la dificultad que encierra el estudio de los alicatados en la Alhambra, uno de los espacios más sugerentes e interesantes es el Baño de Comares. La propia funcionalidad del espacio en época nazarí, su mantenimiento con diferentes funciones tras la conquista cristiana, así como las profundas intervenciones a partir del XVI, han motivado un debate historiográfico sobre la originalidad y cronología de sus alicatados.

\subsection{Historicidad multicultural de un espacio}

Uno de los elementos que sin duda enriquece y llama la atención del Baño de Comares es la historicidad que encierra, esencialmente si pensamos en las importantes intervenciones que vivió tras la conquista cristiana y los usos que pudo tener. Su simbolismo al ser ocupada la Alhambra por los cristianos, su sentido y valor en un espacio regio cristiano, las interpretaciones que predominan sobre los baños y específicamente sobre la singularidad del baño de Comares a lo largo del XVII, las visiones e imágenes románticas y las intervenciones adornistas del siglo XIX, no hacen más que reflejarnos la intensa historia de este espacio

El Baño de Comares presenta a grandes rasgos las estancias habituales para un hammam: el baño cuenta con una primera estancia, bayt al-maslaj o sala de vestuario y de los masajes (conocida como Sala de las Camas); a continuación se dispone bayt al-barid o sala fría, bayt al-wastani o sala templada y por último

22 A.Alh., L-152-1, folio suelto titulado obras en la casa real, letra del XVII. A. Alh., L-152-1 (sobre reparos que necesita la Alhambra, 18 de enero de1644).

23 A.Alh. L-44-6.

24 A.Alh. L-183-2

25 Es el caso del pago de 400 azulejos a medio real cada uno en el año 1750 pero no se especifica para qué espacio, A.Alh. L-53-18.

26 A.Alh. L-53-18. 
bayt al-sajun o sala de agua caliente. En el sur, tras la sala de agua caliente, se ubicaba la caldera y el almacén de la leña, transportada ésta por lo que se conocerá como callejón de los leñadores. El aire caliente circulaba por el hipocausto que se extiende bajo la sala de agua caliente y por parte de la templada. Sería necesario un estudio pormenorizado sobre su tipología con un análisis comparativo con otros baños de la propia Alhambra, cuya presencia es numerosa. Del mismo modo, habría que hacer con baños de otros contextos geográficos y temporales, comparándolo no sólo con los de época nazarí sino también de cronología anterior.

Partiendo del planteamiento que hiciera Manuel Gómez-Moreno Martínez en su trabajo sobre la Granada en el siglo XIII, el baño ya existía en la época de Ismail I (1314-1325) por las características arcaicas de las columnas de la sala templada y por tanto en época de Yusuf I (1333-1354) sería renovado añadiendo la linterna o qubba de la sala de descanso, los capiteles, inscripciones, las yeserías de las galerías superiores de la Sala de las Camas y la cerámica vidriada, tal como indica Basilio Pavón Maldonado. 27 Jesús Bermúdez Pareja, en su artículo sobre el Baño de Comares, recoge y admite las teorías de Manuel Gómez-Moreno. ${ }^{28}$ Para Leopoldo Torres Balbás el baño se levantó en época de Yusuf I y su existencia modificó el eje del Palacio de los Leones. ${ }^{29}$ Rafael Domínguez Casas acepta esta idea al señalar que se suele atribuir a Yusuf I. ${ }^{30}$ Carlos Vílchez Vílchez lo data de época de Yusuf I. ${ }^{31}$ Juan Carlos Ruiz Souza plantea que aunque tradicionalmente se ha atribuido el baño a Yusuf I por algunas piezas datables en esa época, sin embargo apunta que esas piezas pudieron ser empleadas por su hijo Muhammad V, ya que según el autor el hecho de que el baño esté ubicado entre edificaciones muy significativas de Muhammad $V$ hace pensar en él como responsable final de la estructura del baño. ${ }^{32}$ Antonio Malpica recoge las diferentes cronologías, llamando a la prudencia sobre aquellas dataciones basadas sólo en la decoración. ${ }^{33}$ Como vemos, por lo general, el Baño de Comares se ha fechado entre Ismail I y Yusuf I sin haber un consenso claro acerca del período en que se construyó.

Pero más que el debate cronológico sobre su origen, para este trabajo resultan de mayor interés algunas reflexiones sobre su mantenimiento, ya que se invierten grandes cantidades y se muestra una especial atención en preservar y remodelar este espacio que no era frecuente en los palacios cristianos de la época, incluyendo en estas actuaciones los alicatados.

Está claro que hay un interés por el mantenimiento de algunos baños y especialmente en el caso del Baño Real de Comares, incluso en el momento en que se prohíbe el uso de los baños públicos, a finales del siglo XVI, se sigue reparando este baño real. ${ }^{34} \mathrm{El}$ hecho de no ser un espacio público que pudiera fomentar la cohesión entre moriscos explica que no hubiera una imperiosa necesidad en destruirlo como en otros casos. Todo lo contrario. Las remodelaciones llevadas a cabo en el Baño de Comares de la Alhambra no hacían más que exaltar su belleza, quizás en un deseo de aumentar el "carácter exótico" de una estancia poco frecuente en el resto de las residencias palaciegas europeas. ${ }^{35} \mathrm{Sin}$ duda sorprende el mantenimiento e intervenciones del

27 Gómez-Moreno Martínez, Manuel. "Granada en el siglo XIII”. Cuadernos de la Alhambra, Granada, 2, 1966, pp. 3-41. Pavón Maldonado, Basilio. Estudios sobre la Alhambra I. La Alcazaba. El Palacio de los Abencerrajes. Los accesos a la Casa Real Vieja. El Palacio de Comares. El Partal. Granada, 1975, específicamente sobre el Baño de Comares, pp. 72-75.

28 BERMúdeZ PAREJA, Jesús. "El baño del Palacio de Comares en la Alhambra de Granada. Disposición primitiva y alteración”, Cuadernos de la Alhambra, Granada, 10, 1975, pp. 99-116.

29 Torres BalBás, Leopoldo. La Alhambra y el Generalife. Madrid, 1953, pp. 47-48.

30 Domínguez Casas, Rafael. Arte y etiqueta de los Reyes Católicos. Artistas, residencias, jardines y bosques. Madrid, 1993, p. 449.

31 VílchEZ Vílchez, Carlos. Baños árabes. Granada, 2001, p. 42

32 Ruiz SouZA, Juan Carlos. "El palacio de los Leones de la Alhambra: ¿madrasa, zawiya y tumba de Muhammad V?", Al-Qantara, Madrid, XXII, 2001, pp. 77-120.

33 Malpica Cuello, Antonio. La Alhambra de Granada, un estudio arqueológico. Granada, 2002, p. 215.

34 Sobre el mantenimiento de los baños vid. DíEz JoRGE, M ${ }^{\mathrm{a}}$ Elena. El arte mudéjar: expresión estética de una convivencia. Granada-Teruel, 2001,p. 270 y ss.

35 Cfr. DíEz Jorge, Ma Elena. "Purificación y placer: el agua y las mil y una noches en los Baños de Comares", Cuadernos de la Alhambra, Granada, 40, 2004, pp. 123-150. 
Baño de Comares si tenemos en cuenta ideas como las del médico que acompañaba a Carlos V, Luis Lobera quien, y siguiendo las normas de la antigüedad, recomendaba de manera general lo que se debía hacer al utilizar los baños, rechazando y negando la práctica del baño alegando que en España "los señores" nunca lo habían usado. ${ }^{36}$

Manteniendo una duda razonable sobre las causas de su preservación, sin lugar a dudas el baño es uno los espacios en los que se invierte gran esfuerzo y dinero en la época cristiana. Se producen algunos cambios como la unión del horno y las leñeras que en época islámica eran independientes pero que en época cristiana se incorporaron al resto de las salas al derribarse el tabique que las separaba. Otros datos apuntan a usos diversos que en algún momento tuvieron que tener, como por ejemplo la alusión a la cocina de los baños. ${ }^{37}$ Pero independientemente del uso que se diera en época cristiana, en la documentación de ese período siempre aparece nombrado como baños y se asocia e identifica como tal.

Referente al Baño de Comares hemos documentado importantes obras desde fines del siglo XV, esencialmente en lo que llaman Capilla de los Baños, para algunos identificada como la Sala de las Camas, centrándose los trabajos hasta 1500 en la techumbre; obras en el entorno de los baños, fundamentalmente entre 1499 y 1501 en la solería del Patio de Lindaraja o jardín de los baños; otras intervenciones son las llevadas a cabo en los corredores de atajo, en la sala en el pasadizo de los baños, en la escalera que sube de la Capilla de los Baños al Cuarto Dorado. En definitiva, durante la época de los Reyes Católicos, y según la documentación manejada, se aprecia una labor que debió ser intensa y continuada durante unos años en la reforma y adecuación de los espacios circundantes a los baños, especialmente en el jardín de los baños pero también en salas y corredores aledaños. También fueron importantes las obras llevadas a cabo en lo que se conoce como Capilla de los Baños. Además de estos datos concentrados entre 1499 y 1500, pocas noticias hemos encontrado relativas a los baños en época de los Reyes Católicos: la compra en 1499 de un arca de barro para asentar en la pared del baño y en 1501 de 64 tazas que compró la reina para los baños de la Alhambra. ${ }^{38}$

El siglo XVI es el momento de mayor intervención. Se siguen realizando obras en la Capilla de los Baños, específicamente en la armadura. También se asientan ladrillos en las bóvedas de los baños y se encargan diversos trabajos para las puertas y ventanas. La inversión en vidrieras es importante a lo largo de todo el XVI, y por la cantidad debemos entender que no sólo se refiere a las vidrieras de la Sala de las Camas sino también de los corredores y espacios cercanos. También se documentan obras en la mitad del XVI en las yeserías de los baños, indicándose trabajos en los mocárabes y en espacios como la Sala de las Camas. Así mismo hemos recogido diversas obras que durante este período se hacen en los baños, tratándose de intervenciones sin especificar o pequeños arreglos, así como materiales que se pagan tanto para los caños como para la caldera. Sobre obras en el entorno se indican en el cuarto encima de los baños y cuarto junto a los baños. 39

36 Tratado de Luis Lobera de Ávila de 1530, Vanquete de nobles cavalleros, publicado en Augsburgo. Tratado citado por Ruiz Somavilla, $M^{\text {a }}$ José. "Los valores sociales, religiosos y morales en las respuestas higiénicas de los siglos XVI y XVII: el problema de los baños", Dymanis, 12, 1992, pp. 155-187.

37 Nos referimos a la época de los Reyes Católicos y siguiendo la documentación, según AGS, CMC, $1^{\text {a época, }}$ leg. 140

38 Para finales del siglo XV hemos manejado principalmente AGS, CMC-I, leg.140 (corresponde a diferentes años desde 1492 y hasta 1500).AGS, CMC-I, leg. 542, (1492-1521); cuentas en el primer conjunto de pliegos de Juan de Rejón (pagador) de lo que recibió para obras de la Alhambra entre los años 1492 y 1521. AGS, CMC-I, leg. 106 (diversas cuentas de 1484 y 1485, pagos de 1499 y de 1500 donde hay algo de la Alhambra, pagos hechos en 1502 de obras llevadas a cabo en 1501 con algunos datos sobre la Alhambra). AGS C y SR (Casas y Sitios Reales), leg.44, $\mathrm{n}^{\circ} 28,1501$.

39 Para el siglo XVI hemos manejado principalmente los cuadernos de nóminas. A.Alh., L -2-2a, 1537 y 1538 ; A.Alh., L -2-2b, 1539 y 1540; A.Alh., L-2-2c, 1541 y 1542; A.Alh. L-3-5, 1544; A.Alh. L-3-5, 1546; A.Alh. L-5-23, 1553; A.Alh. L-5-40, 1556; A.Alh. L-240-2, 1585; A.Alh. L-240-3, 1585; A.Alh. L-240-4, 1586; A.Alh. L-240-5, 1586. A.Alh. L-240-6, 1587; A-Alh., L-240-7, 1588; A.Alh., L-21-4, nº 3, 1590; A.Alh., L- 6-27, Información del maestro aparejador Juan de la Vega, 1590; A.Alh., L-52-1, 1591 y 1592. A.Alh., L-241-34, 1596 a 1803. Bibliográficamente son interesentes Bermúdez Pareja, Jesús y Moreno Olmedo, Ma Angustias."Documentos de una catástrofe en la Alhambra", Cuadernos de la Alhambra, Granada, 12, 1996, pp. 77-87; y MuÑOZ Cosme, Alfonso. "Cuatro siglos de intervenciones en la Alhambra de Granada, 1492-1907”, Cuadernos de la Alhambra, Granada, 27, 1991, pp. 151-189. 
Durante el XVII se sabe que los baños no se encontraban en muy buenas condiciones y que existían bastante desperfectos, casi amenazando ruina tanto las bóvedas como los arcos. Las intervenciones principales se concentraron en las bóvedas de las calderas de los baños ya que entraba bastante agua, en la colocación de ventanas y puertas, en reparar y blanquear con yeso las bóvedas y en empedrar la zona.

Otra de las actuaciones durante el XVII es el arreglo de los jardines y entrada a los baños sobre todo lo que se refiere al empedrado. Hay que indicar también las importantes intervenciones en los arreglos de cañerías y conducciones de agua -cauchiles de piedra y caños de bronce para las conducciones de varios pilares, entre ellos uno a la entrada de los baños y para la fuente que está en los baños-. En menor medida se trabaja en las vidrieras, siendo mínima la documentación al respecto. ${ }^{40}$

Para el XVIII hemos manejado varios informes sobre el estado de conservación de la Alhambra donde se recogen algunos aspectos interesantes. Por ejemplo se señala que el estado general de las piezas de alicatados en la Alhambra no era bueno y se recomienda reponer. Aunque no se indica nada específicamente de los alicatados de los baños debían estar mal ya que se señala en los informes la situación de ruina de los baños y especialmente de sus paredes interiores y exteriores. ${ }^{41}$

En el XIX será cuando encontremos nuevamente intervenciones importantes. Además de la supresión de un cuerpo en 1827 en la Sala de las Camas, la actuación más relevante fue la de Rafael Contreras, que en realidad parece que afectó más a las yeserías que a los alicatados, aunque se cambiaron algunas piezas ya que por ejemplo sustituyó el friso de azulejos con los emblemas del emperador por las almenillas escalonadas que tiene en la actualidad. La intervención acentúa en exceso el colorido de las yeserías dentro del más puro principio adornista propio de la época, intentando recrear más si cabe la sensación de una cámara de maravillas insospechadas. La intervención de Contreras será consolidada y mantenida por su hijo Mariano Contreras y por Modesto Cendoya. 42

En lo referente a la primera mitad del siglo XX se centró esencialmente en obras de mantenimiento así como intervenciones en las cubiertas y revestimientos exteriores, siendo uno de los problemas más graves el de la humedad. ${ }^{43}$ Entre las intervenciones hay que destacar las llevadas a cabo por Leopoldo Torres Balbás. En 1924 arregló la conducción de agua de la fuente del Patio de Daraja y la de la fuente del Patio de la Reja, adecuándose a la vez la de la "pila de abluciones de los baños", corriendo por primera vez el agua en estas fuentes y pila. ${ }^{44}$ En noviembre de 1924 se comenzó a reparar la parte de los servicios de los baños, o callejón de los leñadores. Pero la intervención mayor de Torres Balbás en los Baños fue la llevada a cabo en 1926, centrada especialmente en los accesos desde el Patio de Comares y donde se planteó el debate sobre cuál podría ser el acceso nazarí desde este lado. En Octubre de 1926 se iniciaron las obras para la fuente de la Sala de las Camas que volvió a echar agua el 9 de octubre.

Algunos informes más actuales del siglo XX indican el grave estado de deterioro de los Baños, habiéndose intervenido recientemente en los alicatados de la Sala de las Camas. ${ }^{45}$

40 Entre la documentación manejada para el siglo XVII, A.Alh., L-153-1, 1611; A.Alh., L-153-2, 1612 a 1620; A.Alh., L-52-4, 1600 y 1601; A.Alh., L-44-3, 1622; A.Alh. L-152-1, 1624; A.Alh., L-241-1, 1624; A.Alh., L-44-6, 1626; A.Alh., L-152, 1635; A.Alh., L-152-1, necesidades y reparos para la preparación de la venida de Felipe IV en 1644; A.Alh., L-152-1, 1680.

41 A.Alh. L-312-1, 1732 a 1745; A.Alh. L-183-2, posterior a 1741; A.Alh. L-53-18, 1748 a 1767; A.Alh. L-175-307, 1784 a 1792.

42 AAlh, L-407, A.Alh.L-345, A.Alh., L-346.

43 Para las actuaciones de principios del siglo XX resulta imprescindible el trabajo de ÁlvAREz LoPERA, José. "La Alhambra entre la conservación y la restauración (1905-1915)", Cuadernos de Arte de la Universidad de Granada, Granada, 29-31, 1977.

44 Sobre las intervenciones de Torres Balbás son fundamentales los Diarios de Obras transcritos en "Diario de obras en la Alhambra, 1924, por Leopoldo Torres Balbás", Cuadernos de la Alhambra, Granada, 2, 1966, pp. 89-111; "Diario de obras en la Alhambra: 1925-1926. Por Leopoldo Torres Balbás", Cuadernos de la Alhambra, Granada, 3, 1967, pp. 125-152; "Diario de obras en la Alhambra: 1930-1936, por Leopoldo Torres Balbás", Cuadernos de la Alhambra, Granada, 5, 1966, pp. 69-94.

${ }^{45}$ Cfr. DE LA TORRE LÓPEZ, Ma José. Estudio de los materiales de construcción en la Alhambra. Granada, 1995. 


\subsection{Debate historiográfico sobre los alicatados del Baño de Comares}

Las hipótesis son varias y principalmente se pueden desglosar en dos: en si existían los alicatados del Baño de Comares ya en época nazarí, o bien si se trata de una obra posterior a la conquista cristiana. A todo ello se van uniendo diferentes matices como el hecho de pensar que puedan tratarse de piezas nazaríes puestas en época cristiana.

En el caso del Baño Comares ha sido unánime destacar las piezas de alicatados, aunque las apreciaciones son diversas. En 1764, Juan Velázquez de Echevarría describió las piezas con el lema del Plus Ultra como añadidos posteriores, entendiéndose que el resto de alicatados los consideraba por lo general nazaríes. ${ }^{46}$ Del mismo modo podemos citar a Simón de Argote quien a principios del XIX destacaba las reparaciones de tiempos del emperador como la "cenefa baja de azulejos sobre la que corre una faja con el mote PLVS OVLTRE", describiendo la trama y medidas de los poyetes de la Sala de las Camas, pero sin mencionar el resto de alicatados. 47

A través de las descripciones de algunos románticos se puede entender que en general consideraron las piezas del baño como nazaríes con algunas reparaciones cristianas. James Cavanah Murphy destaca especialmente de la Sala de las Camas los alicatados señalando el uso del negro, verde, amarillo y blanco enmarcado en verde, constituyendo un testimonio, cercano o no a la realidad, pero anterior a la importante transformación que llevaría a cabo el arquitecto Rafael Contreras. En el interior de lo que considera propiamente el baño, señala en la plancha XX que el suelo y las columnas son de mármol blanco, y destaca la belleza de los alicatados que llegan "hasta las cornisas", y efectivamente en el dibujo los lleva hasta la cornisa lo que debemos entender a priori como una interpretación lejana de la realidad, además de que la trama de alicatados que dibuja difiere de la que vemos hoy en día. En la plancha de la sala templada dibuja dos pequeñas piletas (plancha XXI), destacando las columnas que a pesar de su delgadez pueden soportar un gran peso; nuevamente lleva los alicatados hasta las cornisas y con el mismo dibujo que en la plancha anterior (Ilustración 1). En la plancha XXIII, Murphy representa una de las pilas de la sala caliente como "baño del rey", que sería la ubicada a la izquierda una vez que entramos en dicha estancia; del dibujo llama la atención que no represente los alicatados que hay en el paño junto al arco de comunicación con la sala templada ni los azulejos del intradós de dicho arco; la trama de alicatados se basa para el autor en dibujos romboidales más alargados de lo que presenta la realidad, además de rematarla con una cenefa de almenillas escalonadas inexistente en la actualidad. En la plancha XXIV describe el "baño de la reina" como el más ricamente ornamentado con dorados y porcelana; los muros están cubiertos hasta la cornisa de preciosos mosaicos blancos y negros. Las piezas de alicatados que señala son blancas y negras y aunque si van más en consonancia con el tipo de entramado geométrico que hay en la realidad, sin embargo las que contemplamos hoy en día tienen una mayor variedad de colores. ${ }^{48}$

En el dibujo de Owen Jones aparecen las diferentes salas con los alicatados, má cercano a la realidad de lo que dibujara James Cavanah Murphy (Ilustración 2). Es curioso que nuevamente, al igual que también hará Girault Prangey, aparezcan las almenillas escalonadas en vez de los azulejos con los signos del "PV" en la sala templada, o las almenillas escalonadas en la sala caliente, cuando en la realidad tiene otro tipo de cenefa. ${ }^{49}$ El dibujo que realiza y destaca del pavimento que rodea la fuente en la Sala de las Camas sí es la misma trama que hoy vemos (lámina XLIII del volumen I) (Ilustración 3). En la lámina L del volumen II recoge detalles de los alicatados de los baños, siendo el número LXXXVII la misma trama que aparece tanto en la Sala de las Camas como en la pila mayor de la sala caliente, aunque los colores parecen

46 VelázQuez de Echevarría, Juan. Paseos por Granada y sus contornos. Granada, 1993.

47 Argote, Simón de. Nuevos paseos históricos, artísticos, económico-políticos por Granada y sus contornos. Granada, 1985. Se suele adscribir a los dos primeros tomos la fecha de 1807.

48 Murphy, James Cavanah. The Arabian antiquities of Spain. London, 1815.

49 Prangey, Girault de. Impressions of Granada and The Alhambra. Hampshire, 1996 


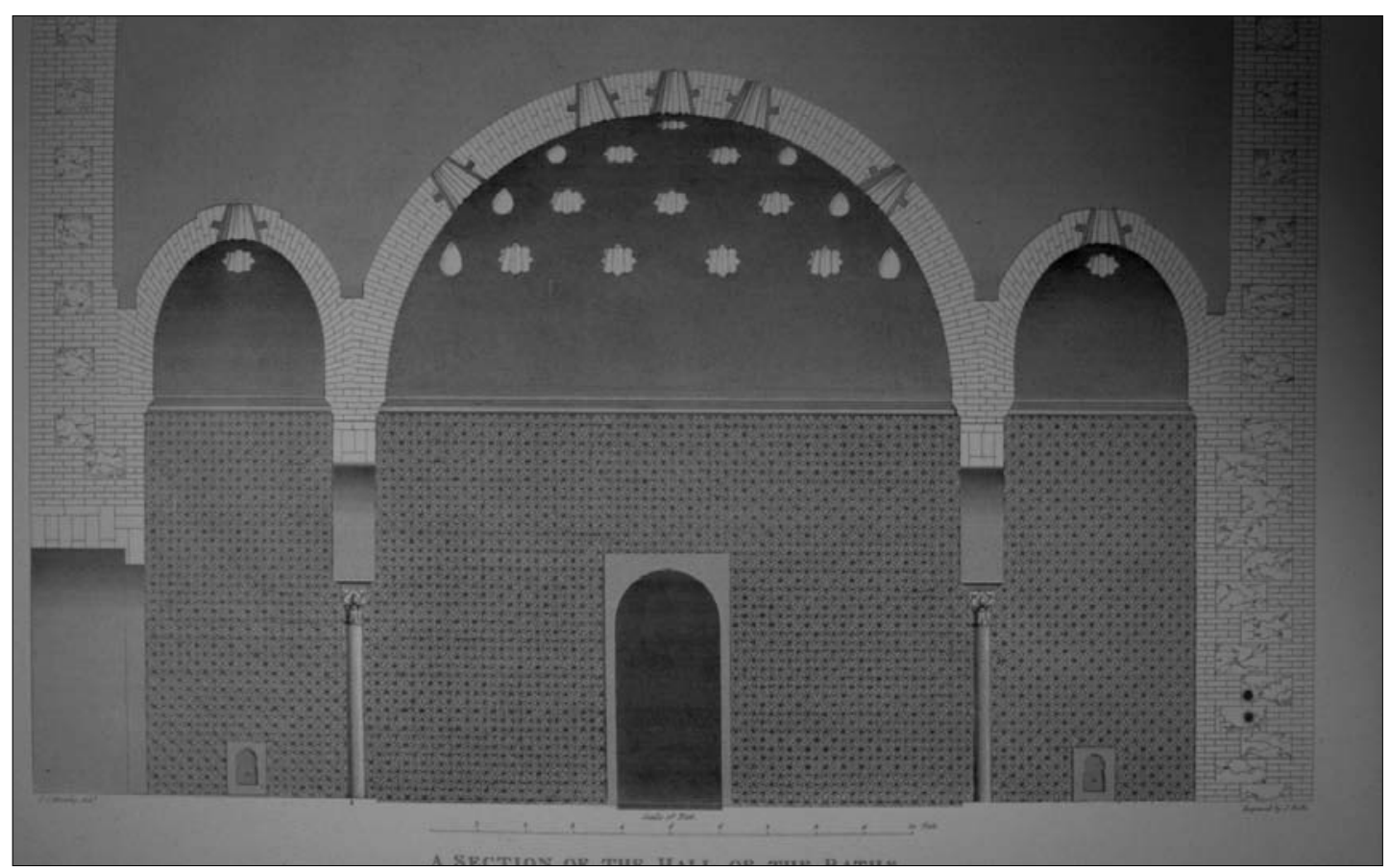

Fig. 1. Plancha XXI en The Arabian antiquities of Spain, de James Cavanah Murphy, publicado en Londres en 1815. (Foto: $M^{\mathrm{a}}$ Elena Díez Jorge).

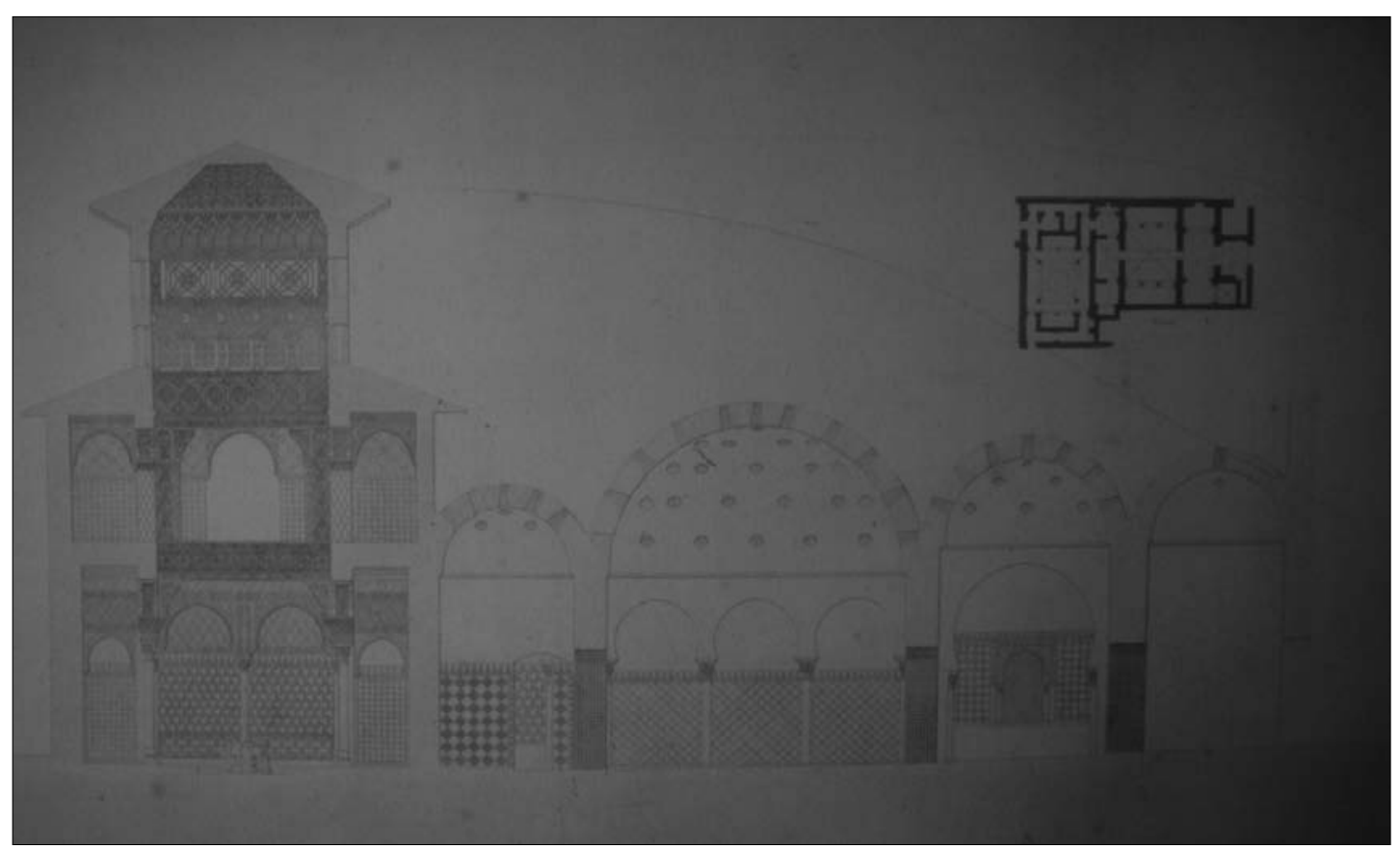

Fig. 2. Dibujo XXVI en Jones, Owen y Goury, Jules. Plans, elevations, sections, and details of the Alhambra. From drawings taken on the spot in 1834 and 1837 by Owen Jones. London, 1842-1845. (Foto: $\mathrm{M}^{\mathrm{a}}$ Elena Díez Jorge).

AEA, LXXX, 317, ENERO-MARZO 2007, 25-43, ISSN: 0004-0428 
ser más bien recreaciones que buscan visualizar una composición simétrica. ${ }^{50}$ Alexandre Laborde en Voyage pittoresque et historique, presenta en la Sala de las Camas una entrada lateral inexistente en la actualidad, mientras que la sala templada y caliente es dibujada con una cenefa de triángulos equiláteros en vez de la cenefa con las siglas "PV" que contemplamos hoy en día. ${ }^{51}$ Richard Ford simplemente indica que los azulejos del baño son dignos de notarse (Ilustración 4). ${ }^{52}$ Como vemos, todos eliminan de sus dibujos y descripciones la cenefa con el lema "PV" en bayt al-wastani, quizás en un alarde de mayor islamización del espacio.

Más allá de la historiografía romántica, diferentes autores granadinos a lo largo del siglo XIX y principios del XX precisaron más datos acerca de la cronología. Así, para Francisco de Paula Valladar los revestimientos de alicatados de los poyos de las camas son posteriores a la conquista cristiana, señalando que en otras zonas de los baños sí hay alicatados que son nazaríes como la mayoría de las piezas del pavimento a excepción de las piezas que rodean la fuente con la cenefa alusiva al Plus Oultre de la época del emperador. Respecto a los alicatados de las siguientes salas señala que son zócalos de malos azulejos de los llamados del Renacimiento, en cuyas labores se leen muy repetidas dos letras, P.V, que según el autor deben ser iniciales de Phelipe V ó abreviaturas de Plus Ultra. Además, Valladar, en su Guía de Granada, señala que antes de bajar por la escalera a la Sala de las Camas, hay un aposento del que existen restos de "azulejos cuadrados" que se conservan en el museo. Asimismo recoge noticias documentales sobre el hundimiento de los alicatados del pavimento de la Sala de las Camas y de las reformas en el baño con la venida de Felipe V, atribuyendo el autor a este momento "rastros en los azulejos de las estancias". 53

Leopoldo Torres Balbás señala que las piezas de alicatados que rodean la fuente de mármol en la Sala de las Camas son de gran belleza y las cataloga como obra del XVI, aunque siguiendo la tradición islámica; del resto de alicatados de los baños no menciona nada. ${ }^{54}$ Jesús Bermúdez Pareja, en su texto sobre el Palacio de Comares y el de los Leones, considera que las puertas, pilas de mármol y arrimaderos de cerámica son de época de Carlos V, quien alteró la decoración del Baño. ${ }^{55}$ En su artículo sobre el Baño de Comares señala que los zócalos de cerámica de las cámaras de vapor del baño son nazaríes y moriscos, pero responden a una obra de embellecimiento morisco ya que los paramentos debieron ser encalados en el período nazarí, atendiendo a que las altas temperaturas así lo requerían. De este modo, el zócalo de alicatado que hay en la primera cámara de vapor con la pileta de mármol es morisco; menciona también el nicho revestido de alicatado en el llamado baño de la sultana y en el que se regulaba el abastecimiento de agua del depósito; también en la otra pileta de la sala caliente hay un nicho con las llaves de paso para los grifos de agua fría y caliente que está alicatado; menciona la guarnición de cerámica cristiana de la arista del arco del horno ya que, según el autor, los cristianos, al adaptar el baño, dejaron diáfano el arco del muro medianero entre el horno y la sala caliente -a modo de chimenea- y así se hizo en época de Carlos V, pero luego se volvió a cerrar aunque dejando a la vista dicha arista de cerámica; a uno y otro lado del arco del horno menciona las tacas revestidas de alicatado.

Para Basilio Pavón Maldonado hay alicatados puestos en época nazarí y específicamente en época de Yusuf I; Pavón hace un estudio muy interesante en su trabajo sobre el Palacio de Comares de los alicatados, sacando las tramas y comparándolas con otros paños de alicatados en la Alhambra; podemos afirmar que es de los pocos que se acerca a estudiar los alicatados de forma más profunda; mantiene que los zócalos más

\footnotetext{
50 JoNES, Owen y Goury, Jules. Plans, elevations, sections, and details of the Alhambra. From drawings taken on the spot in 1834 and 1837 by Owen Jones. London, 1842-1845. Hay una edición facsímil: CAMPos Romero, Ma Ángeles (ed.) Planos, alzados, secciones y detalles de la Alhambra. Madrid, 2001.

${ }^{51}$ LABORDE, Alexandre. Voyage pittoresque et historique de l'Espagne. París, 1806-1820.

52 Ford, Richard. Granada. Madrid, 1955 (se trata de un facsímil de la edición de 1855, que supuso la tercera y última edición que en vida revisó y amplió).

53 Valladar, Francisco de Paula. Guía de Granada. Historia, descripciones, artes, costumbres, investigaciones arqueológicas. Granada, 2000. ed. facsímil.

54 TORRES BALBÁs, Leopoldo. Op. cit.

55 Bermúdez Pareja, Jesús. Palacios de Comares y Leones. Granada, 1972.
} 


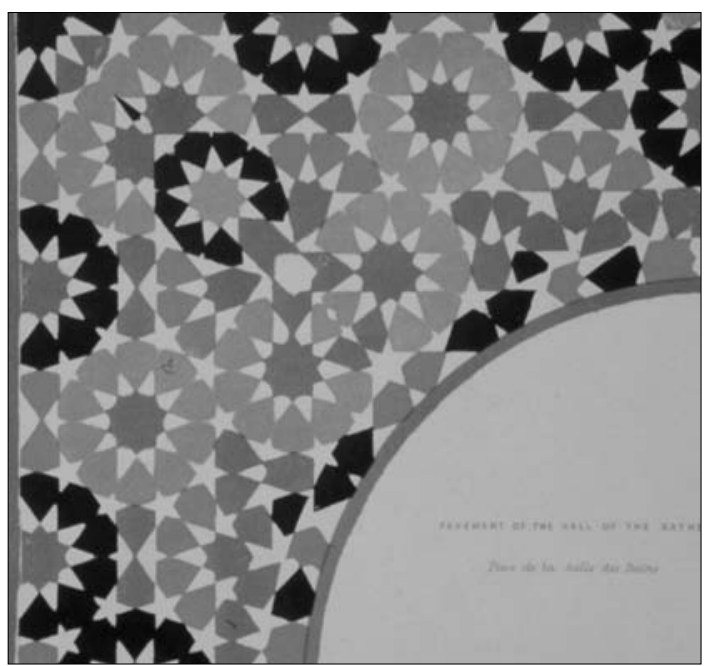

Fig. 3. Figura XLIII en Jones, Owen y Goury, Jules. Plans, elevations, sections, and details of the Alhambra. From drawings taken on the spot in 1834 and 1837 by Owen Jones. London, 1842-1845. (Foto: $\mathrm{M}^{\mathrm{a}}$ Elena Díez Jorge).

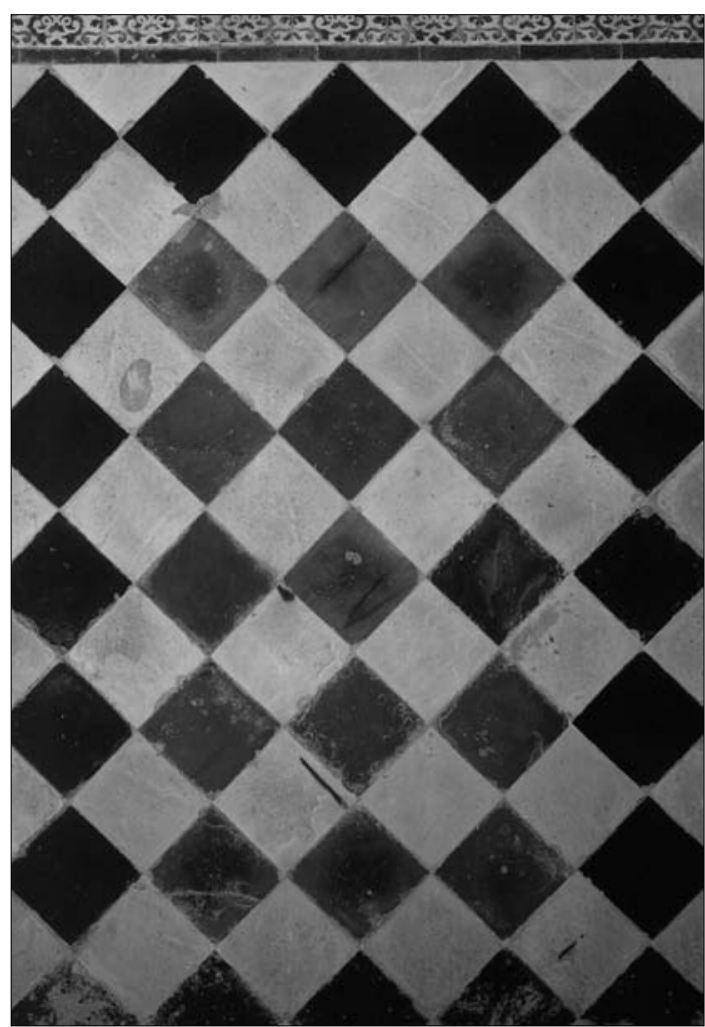

Fig. 6. Alicatados en una de las salas contiguas a la Sala de las Camas. Baño de Comares. Alhambra de Granada. (Foto: Vicente del Amo).

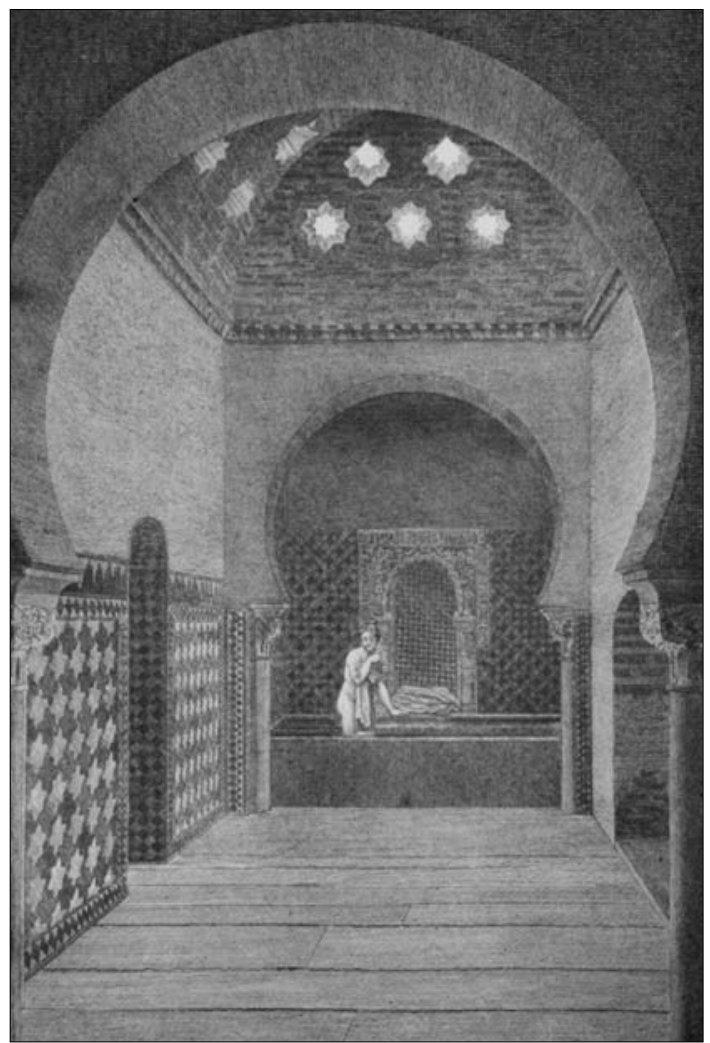

Fig 4. Plancha LVIII en LABORDE, Alexandre.

Voyage pittoresque et historique de l'Espagne. París, 1806-1820. (Foto: $M^{\mathrm{a}}$ Elena Díez Jorge).

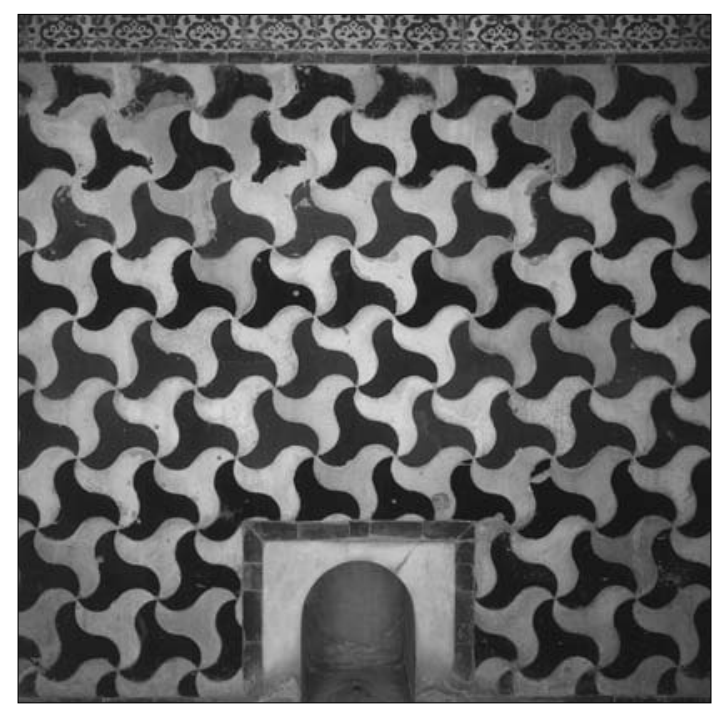

Fig. 5. Alicatados en una de las salas contiguas a la Sala de las Camas. Baño de Comares. Alhambra de Granada. (Foto: Vicente del Amo). 
sencillos del Salón de Comares están todos repetidos en el Baño Real, afirmando que "unos mismos artistas decoraron ambas construcciones". 56

Para Miguel Ángel Rivas las lumbreras cerámicas poligonales del baño de San Francisco de lados curvos y vidriadas, de policromía azul y blanca, y otras piezas de cerámica, son semejantes a las del Baño de Comares, indicando que ambas son de la época de Yusuf I. ${ }^{57}$ Mientras que para Rafael Domínguez Casas, y atendiendo a los pagos de azulejos a Antón Jiménez y a Juan Ruiz de la Cruz en los primeros años tras la conquista, fue en este tiempo cuando se debieron poner los zócalos y arrimaderos de las tres salas. Además, en la descripción que hace del baño señala que pegados a los muros de las tres salas se dispondrían asientos o poyos para los bañistas pero que fueron eliminados más tarde cuando se decoraron los zócalos con azulejería. 58

Hay una primera aproximación importante y muy sugerente que es la de José Manuel Gómez-Moreno Calera. Frente a la tradicional hipótesis sobre una reposición completa de la cerámica de los baños en época cristiana plantea que a pesar de las importantes reposiciones del XVI y del XIX estas salas pueden conservar en algunas zonas lo esencial de su trama nazarí. El autor recoge la controversia sobre el tema y las posiciones contrapuestas de los investigadores. ${ }^{59}$ Sin lugar a dudas me adscribo al planteamiento de GómezMoreno Calera para quien además de poder estar presente una trama nazarí en los zócalos del Baño de Comares pueden también haberse utilizado en este espacio piezas nazaríes de otras zonas de la Alhambra, idea ya enunciada por Jesús Bermúdez Pareja.

En definitiva, hay autores que indican que en los alicatados del Baño de Comares hay piezas que son posteriores a la conquista cristiana, caso por ejemplo habitual que se señala de los poyos de la Sala de las Camas y las piezas que rodean la fuente de dicha sala, combinando con piezas que son de época islámica. En la misma línea está José Manuel Gómez-Moreno Calera al señalar que evidentemente hay una reposición cristiana importante pero que puede conservarse en algunas zonas lo esencial de lo nazarí. También está la teoría de que casi todos los alicatados son de la época cristiana, caso de Francisco de Paula Valladar, Jesús Bermúdez Pareja o Rafael Domínguez Casas. Menos seguida es la teoría de que en su mayoría son nazaríes, defendida en este caso por autores como Basilio Pavón Maldonado y por Miguel Ángel Rivas esencialmente. Por tanto, no hay consenso en la comunidad científica sobre su época y procedencia.

\subsection{Los alicatados del Baño de Comares, ¿nazaries o cristianos? Aportaciones documentales}

Lo primero que debemos plantear es si contamos con ejemplos del uso de alicatados, mosaicos y piezas vidriadas en un baño. Sabemos de la decoración de los baños griegos con frescos y los suelos con mosaicos. ${ }^{60}$ Entre otros ejemplos se citan casos como las termas de Cisiarii en Ostia con ejemplo de mosaico, o los mosaicos omeyas en los pavimentos de los baños de Khirbat al Mafjar con caracteres geométricos y policromos. ${ }^{61}$ En el baño de Qusayr 'Amra hay una gran variedad de decoración: algunos suelos de sus salas estaban cubiertos de mármoles, y se cubría también los zócalos de las paredes hasta el comienzo de las zonas decoradas por pinturas o mosaicos según los casos; además, algunas de las salas tienen su piso recubierto de mosaicos. ${ }^{62}$ En cuanto a hammam de épocas posteriores se constata que sí había decoración, sobre todo

56 Pavón Maldonado, Basilio. Op. cit.

57 Rivas HernándeZ, Miguel Ángel. Op. cit.

58 Domínguez CASAs, Rafael. Op. cit., p.450.

59 Gómez-Moreno CALERA, José Manuel. Reflexiones sobre la cerámica arquitectónica mudéjar en la Alhambra. Actas del XIII Congreso CEHA. Granada, 2000, pp. 123-133.

60 Es el caso de los baños griegos en Egipto que menciona PAUTY, Edmond. Les Hammams du Caire. El Cairo, 1933, pp. 12-13.

61 LaVAGNe, Henri. La mosä̈que. France, 1987, p.45 y 94.

62 Almagro BASCH, Martín et alii. Qusayr' Amra: residencia y baños omeyas en el desierto de Jordania. Madrid, 1975. 
en el pavimento, aunque fue menos común la decoración sobre las paredes. Interesantes son los numerosos ejemplos que recoge Edmond Pauty de pavimentos con mosaicos en hammans de El Cairo, especialmente en bayt al-maslaj, así como algunas referencias a la decoración con piezas de colores en las paredes. ${ }^{63}$ Aunque posteriores, hay casos de gran belleza como el Hammam al-Basha en Acre (otomano, del siglo XVIII) que tiene una gran decoración no sólo en los techos sino también con alicatados de cerámica coloreada cubriendo la mitad baja de las paredes. ${ }^{64}$ Son simplemente algunos casos que forman parte de un legado común mediterráneo.

Si examinamos las fuentes árabes encontramos el uso de determinados materiales que daban colorido al baño, y entre ellos se describen piezas coloreadas y vidrios teñidos para los baños, aunque sin poder afirmar que se trata de cerámica vidriada. En los textos se señala frecuentemente el uso del mármol para suelos y paredes de los baños islámicos.

En la Península Ibérica contamos principalmente con baños con pinturas murales. En el Bañuelo, Alhammam al-Yawza, en Granada, en el estuco de las paredes quedan restos de policromía en bermellón. Un baño decorado con pinturas es el del Palacio de Villardompardo en Jaén; se cree construido en el siglo XI pero redecorado en el siglo XII; se trata de pintura mural de círculo de estrella y decoración floral central (decoraciones que formarían parte de la cúpula central de la sala caliente); parece que también las paredes del vestidor y sala templada estarían pintadas; en el bayt al-maslaj se pinta una decoración simulando unas arquerías con capiteles del tipo nazarí, suponiéndose que estas pinturas corresponde a una redecoración. ${ }^{65}$ En decoración en un baño hay que destacar el conjunto de pintura mural de los Baños de Tordesillas, datados en época de Pedro I y María de Padilla, con una decoración de entrelazos, elementos heráldicos y remates de pájaros y flores.

Basilio Pavón, en su estudio sobre la Alcazaba de la Alhambra, señala que el Baño de la Alcazaba y el de Abencerrajes son contemporáneos y que la sala caliente del de Abencerrajes tenía suelos y paredes con pintura roja y que también lo debía tener el de la Alcazaba; aún pueden verse en el baño de la Alcazaba losetas vidriadas. Estas comparaciones con otros baños de la Alhambra resultan interesantes, sobre todo si tenemos en cuenta que en el Baño de la Mezquita hay una pililla revestida de piezas vidriadas con dibujos de estrellas y cuadros; en el Baño de Dar al-Arusa se conserva una solería de piezas vidriadas en colores blanco, azul y negro espiga; o que el Baño del Convento de San Francisco así como los de Abencerrajes, son de los más importantes en cuanto a decoración de alicatados en sus pavimentos y zócalos.

Por tanto, la decoración en los baños era frecuente y habitual, haciéndose uso de la pintura mural, aunque en los baños de la Alhambra domina el uso de los alicatados. Partiendo de esta premisa, interesaría avanzar en el estudio del aspecto más puramente estilístico de los alicatados y ello debería implicar un análisis de las tramas apoyándonos además en las técnicas para poder establecer su cronología.

En este sentido, Pavón Maldonado hace un avance muy interesante sobre las tramas de alicatados. El autor señala en los Baños de Comares hasta diez dibujos diferentes. Los más vistosos son según el autor para la Sala de las Camas. Una trama de cuadritos negros, verdes y blancos señala que es frecuente en los baños más antiguos de la Alhambra. La trama de hélices de tres puntas curvas que se encuentra en la Sala de las Camas, también la localiza el autor en las alacenas del pórtico norte de Comares. Las piezas de tres picos que vemos en los poyos de las camas, los compara con los de las tacas del arco de ingreso a Comares. Las estrellas de ocho puntas con líneas paralelas que están en bayt al-wastani se repiten en el Baño de Muhammad III de la Calle Real. Los octógonos entre estrellas de cuatro puntas y las piezas en forma de trébol de cuatro hojas señala que son nuevos en la Alhambra. De las piezas de dos picos salientes y dos entrantes señala que también están en las tacas del arco de ingreso de Comares. En los camerines primeros (a derecha e izquierda) del Salón de Comares se repiten tramas de alicatados del Baño Real (se trata de las piezas de tres

\footnotetext{
63 Por ejemplo recoge la cita de Abd el-Latif quien describe un baño de su tiempo (1160-1231) donde las paredes estaban cubiertas con piezas de colores. PAUTY, Edmond. Op. cit., p, 25.

64 Dow, Martin. The islamic baths of Palestine. Oxford, 1996, p. 5.

65 RALlo Gruss, Carmen. Op. cit., p. 181 a 183.
} 
picos). En definitiva, el autor indica que algunas tramas de alicatados de los Baños repiten modelos de otros espacios de la Alhambra frente a otras que significan una novedad, como las que se encuentran en la pila más pequeña de la sala caliente. 66

Este primer inventario que realiza Pavón debería ser completado de forma más exhaustiva, aunque ello se escapa del alcance de este trabajo ya que nos hemos centrado por ahora en la documentación de archivo.

Ante la falta de especificación de los datos que nos ofrece la documentación no podemos afirmar que exista algún caso en la Alhambra que en los años posteriores a la conquista cristiana pusieran alicatados en una estancia que no los tuviera. Pero no negamos que exista esta posibilidad cierta ya que en los años posteriores a la conquista se constata una cantidad importante de piezas que nos hace pensar en algo más que en reparaciones. Por contra la propia documentación también nos indica el interés por mantener las obras tal como estaban hechas, y podemos pensar que se mantuvo el mismo criterio para los alicatados. Así pues, si partiéramos de la idea de que los alicatados del Baño de Comares son nazaríes, o al menos que existiera algún testimonio de alicatados, no es extraño pensar en las reposiciones de las piezas a lo largo de la época cristiana. Pero tampoco podemos descartar que todo los alicatdos fueron puestos en época cristiana. Independientemente de que en origen el Baño de Comares tuviera alicatados o no, lo que sí es cierto es que gran parte de los conservados en la actualidad son puestos en época cristiana, atendiendo esencialmente a la documentación de archivo.

Hay que señalar que hemos manejado principalmente finales del siglo XV y siglo XVI por entender que son los momentos principales de actuaciones en los baños en lo que a piezas de alicatados se refiere. Del siglo XVII y XVIII se han realizado catas puntuales en legajos donde entendíamos que podía haber noticias, especialmente lo referente a cuentas de obras. Del siglo XIX y XX se han manejado algunos informes de arquitectos y conservadores de la época. Por tanto el trabajo se ha centrado esencialmente en el momento de transición del XV al XVI por ser aquél en el que podíamos vislumbrar con más claridad si los alicatados eran reposiciones cristianas o bien estaban ya en la fábrica nazarí.

De 1492 a 1496 no documentamos nada acerca de los alicatados de los baños. Sí hay datos de alicatados pero no se especifican espacios. Ya en 1497 documentamos el pago por una serie de azulejos para los Baños, piezas que son traídas desde Andújar -se trata de 12 varas por las que se paga 2530 maravedíes-; prácticamente constituye el único dato del siglo XV ya que otros datos hacen referencia a la huerta de los baños. ${ }^{67}$ A partir de 1500 tenemos más referencias; las primeras siguen siendo al jardín o huerta de los baños que debe ser el de Lindaraja y se trata de soladores cortando ladrillo, alizares y azulejos.

Los encargos principales se hacen a Isabel de Robles, especialmente desde 1537 y hasta 1542. Se trata de importantes partidas de piezas que nos confirman que no se trató de una simple reparación de piezas sino que o bien se renuevan gran parte de los alicatados o bien más que una reposición se trató de una creación nueva. Hemos contabilizado 15.639 piezas vidriadas en los pagos a Isabel de Robles desde 1537 a 1542 . La variedad de formas y colores nos hacen pensar en esta "empresaria" como la principal suministradora de piezas para el Baño de Comares: azulejos pequeños, medianos y grandes, alizares, piezas de corona, llaranja$d a$ (sic), piezas de triángulos de todos los colores, azulejos de hechura de hoja de higuera, azulejos de hechura de pie de águila, azulejos cuadrados, cintas, azulejos de tablilla y olambres.

Tras estos años hay una laguna documental en lo que a cuentas se refiere hasta 1585 . A partir de entonces se documentan trabajos esporádicos en los baños, tanto de obra como de alicatados. Los pagos de los encargos hechos se concentran, en lo que a alicatados y azulejos se refiere, en el Palacio de los Leones y en el Palacio de Comares.

Durante el siglo XVII, y de manera general, se documentan pagos conjuntos para el Jardín de los Mármoles y para la entrada a los baños al maestro azulejero Pedro Tenorio. Al mismo maestro se le encargan piezas para forrar las paredes de los baños pero se trata de pocas piezas - azulejos sin especificar, olambres,

\footnotetext{
66 PAVÓn MALdonado, Basilio. Op. cit., p. 72-75.

67 AGS,CMC-I, leg. 140, pliego cuentas relativas a 1497, fol. 23; el 25 de Julio del año siguiente vende cuatro varas de azulejos para la Alhambra aunque no se especifica si son para los baños.
} 


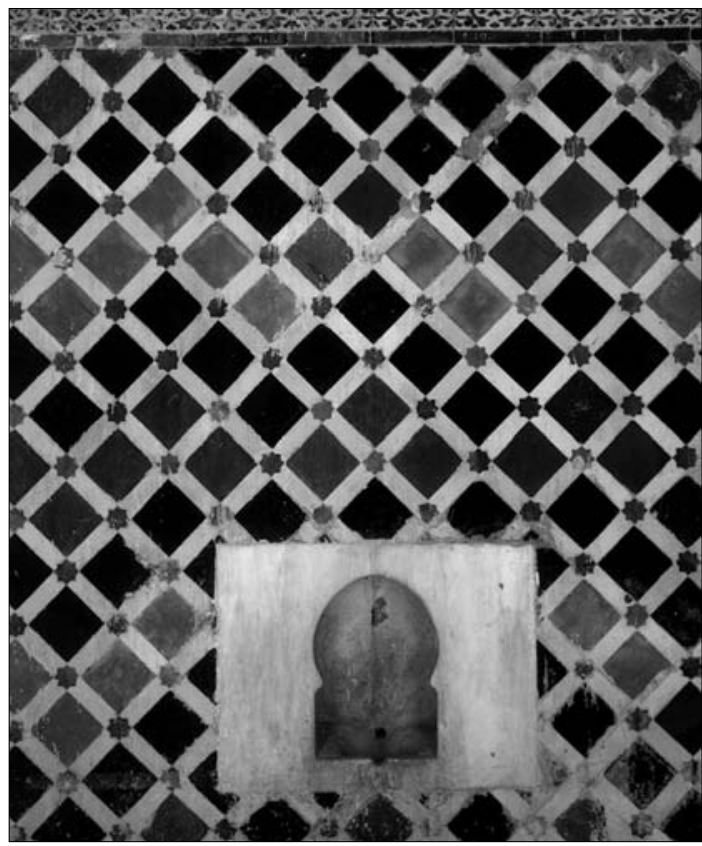

Fig. 7. Alicatados en bayt al-wastani. Baño de Comares.Alhambra de Granada. (Foto: Vicente del Amo).

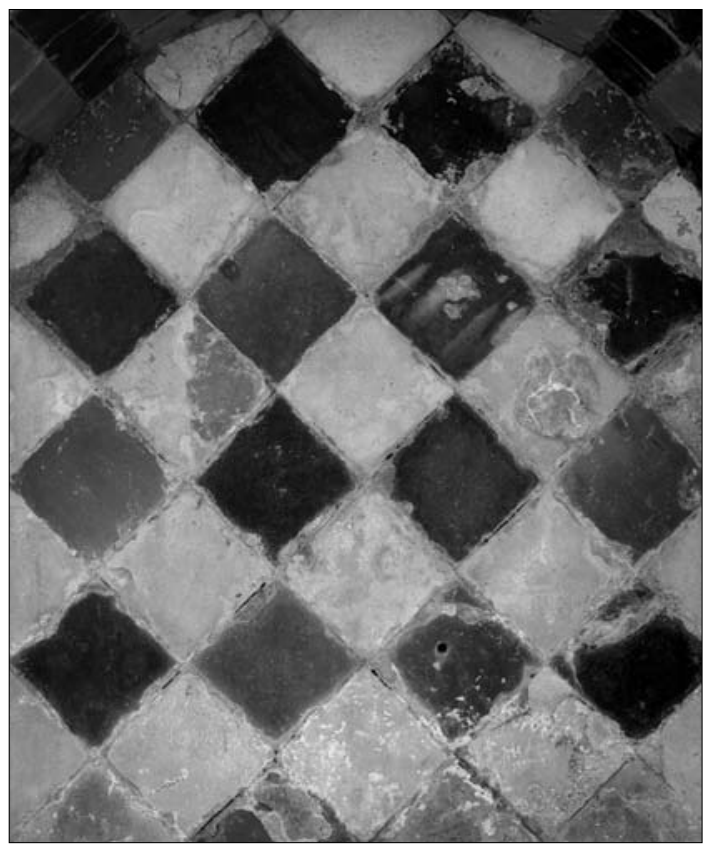

Fig. 9. Detalle hornacina en una de las pilas de baytal-sajum. Baño de Comares. Alhambra de Granada. (Foto: Vicente del Amo).

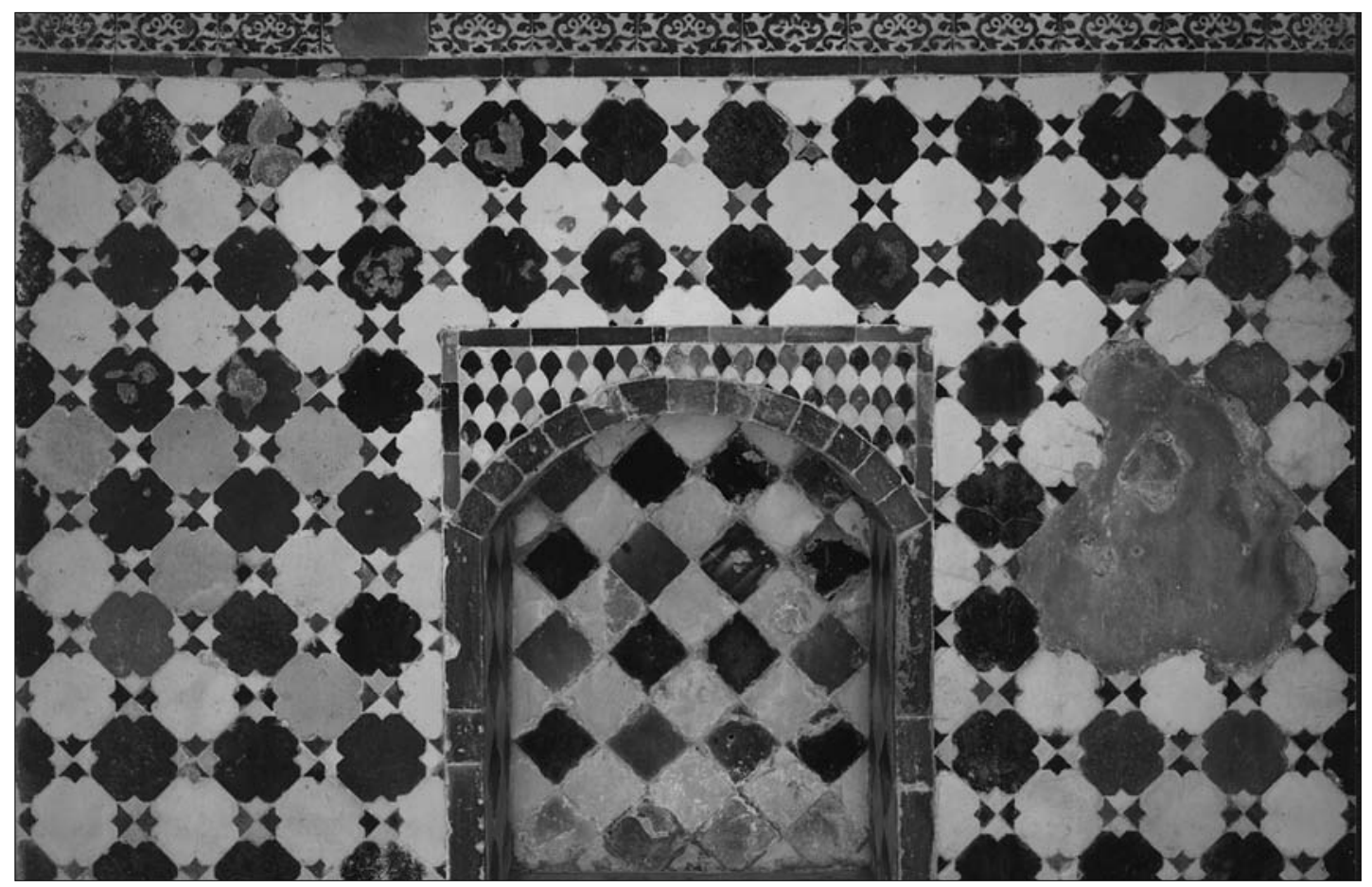

Fig. 8. Alicatados en una de la pilas de bayt al-sajun. Baño de Comares. Alhambra de Granada. (Foto: Vicente del Amo). 
verduguillos y alizares- y además se documenta a un solador por trescientas piezas que soló en los aposentos de los baños. ${ }^{68}$ Destacamos un documento sobre reparos y pagos en el XVII ante el mal estado de los alicatados en los baños ya que se señala que era necesario enchapar fragmentos del Cuarto de las Camas y las propias camas, los cuartos de los baños, el cuarto que sigue al de las Camas del que se indica que le faltan azulejos ( 8 varas) así como al que denominan el Baño de la Reina que también le faltan azulejos(7 varas) ${ }^{69}$.

En las catas realizadas en la documentación del siglo XVIII no hemos encontrado hasta la fecha referencias a intervenciones en los alicatados de los baños. En el XIX los datos se centran fundamentalmente en la intervención de Rafael Contreras, quien cambia, entre otras piezas, las cenefas con el símbolo de Plus Ultra en la Sala de las Camas por almenillas escalonadas.

Durante el XX encontramos principalmente las referencias de los diarios de obras de Torres Balbás. Destacamos de sus noticias su indicación de que se descubrió que la solería de mármol estaba por encima del nivel de zócalos de alicatados; es decir, se trata de un suelo posterior a los alicatados porque probablemente aquél sería con piezas de alicatados y barro; no olvidemos que se documentan muchas partidas de azulejos para los suelos de los baños a lo largo del XVI. Interesante resulta de los diarios de obras que indique la existencia de zócalos de azulejos bajo el hormigón en el acceso desde el Patio de Comares hasta la sala de reposo. Pero si Leopoldo Torres Balbás fue un ejemplo en cuanto a la documentación que dejó de sus intervenciones, sin embargo algunas de sus actuaciones son discutibles ya que, en lo que se refiere a los alicatados, repuso piezas que faltaban con fondos de los almacenes.

Pero además de los informes, de los cuales se debe seguir haciendo un vaciado de información, hemos manejado otra referencia como son algunas fotografías publicadas. El fin era apreciar a través de ellas reposiciones e intervenciones no documentadas a través de los informes. En ese sentido, el mayor número de fotografías corresponde a la sala templada. En dichas fotografías se aprecia que algunas zonas del lienzo oeste han sido retocadas, pero especialmente se testimonian intervenciones desde las fotografías que publicara Jesús Bermúdez Pareja en comparación a la situación actual. El deterioro es claro en el muro noroeste de la Sala Templada; en los paños sureste de la Sala templada también se aprecia un grave deterioro, especialmente al comparar las fotos de 1930 con la actualidad. Se han repuesto piezas desde 1930 en el arco de transición de la Sala Templada a la Sala Caliente. Ha habido algunas reposiciones en la Sala Caliente, específicamente en la pila grande, a la vez que un mayor deterioro en los paños cercanos al nicho de la pila grande. Todo ello nos lleva a afirmar que ha habido reposiciones de piezas sueltas desde el segundo tercio del siglo XX pero sin ningún criterio más que reintegrar la falta. Paralelamente a estas reposiciones, en otras zonas se ha producido un mayor deterioro especialmente por sales de la humedad.

Todas estas referencias nos llevan a un planteamiento claro. En primer lugar la necesidad de realizar un corpus de los alicatados en la Alhambra. La importancia de los alicatados en la Alhambra no se centra exclusivamente en los de época nazarí sino también en el proceso de continuidad y transformaciones en época cristiana, siendo el siglo XVI el momento álgido de elaboración de piezas vidriadas para la Alhambra. A partir de la documentación de archivo que hemos manejado, sabemos que tras la conquista cristiana las piezas vidriadas se encargan primeramente a maestros de Jaén y Sevilla y posteriormente a maestros de Granada, esencialmente el taller de Robles, de Hernández y de Tenorio, todos ellos emparentados. Muchas de las piezas que se encargan no se especifica el lugar al que van destinadas más que son principalmente para el Palacio de Comares y en menor medida para el Palacio de los Leones. A ello hay que unir la dificultad para saber si algunos paramentos y pavimentos estaban forrados con piezas vidriadas en época nazarí o bien lo fueron en época cristiana.

En segundo lugar, y específicamente en el Baño de Comares, debemos destacar el debate historiográfico sobre el origen de los alicatados. En el XVIII se consideraron esencialmente nazaríes con reposiciones cristianas. Para los románticos eran esencialmente alicatados nazaríes. En el siglo XX las hipótesis van des-

68 A.Alh., L-44-6

69 A.Alh., L-152-1, cuaderno de reparos en las casas reales, siglo XVII. 
de ser nazaríes y moriscos pero puestos todos en época cristiana hasta seguir manteniendo que su origen y colocación fue esencialmente en época nazarí.

La documentación de archivo nos ha mostrado que durante la época cristiana, esencialmente siglo XVI, se encargó tal cantidad de piezas para los baños que sin duda gran parte de los alicatados que vemos hoy en día en los Baños de Comares son de ese momento. Sin embargo desconocemos si se reutilizaron algunos paños nazaríes y si los alicatados cristianos venían a reponer o sustituir unos nazaríes, ya que no era infrecuente que el hammam tuviera alicatados en sus zócalos. En la propia Alhambra hay otros ejemplos de zócalos de baños con alicatados nazaríes. Sí esta claro que después de la gran intervención de mitad del siglo XVI, hay contínuas y pequeñas reparaciones hasta la actualidad, utilizándose en épocas más recientes algunas piezas de los fondos museísticos para salvar las lagunas, criterio que no compartimos especialmente si no se ha realizado primeramente el inventario y catalogación de los alicatados que permita conocer su origen e historia. Por ello concluimos que en el caso de los alicatados del Baño de Comares hay que huir en las futuras intervenciones de la reposición de piezas. Se han hecho ya demasiadas intervenciones y en general sin ningún criterio más que el de reintegrar las faltas, sin distinción alguna de lo que se repone y sin antes haber hecho la catalogación necesaria de los alicatados en la Alhambra. 